\title{
In-situ HT gas sensors: Continuous monitoring of the combustion quality of different wood combustion systems and optimization of combustion process
}

\author{
Heinz Kohler ${ }^{1}$, Binayak Ojha ${ }^{1}$, Navas Illyaskutty ${ }^{1}$, Ingo Hartmann ${ }^{2}$, Christian Thiel ${ }^{2}$, Konrad Eisinger ${ }^{2}$, \\ Markus Dambacher ${ }^{3}$ \\ ${ }^{1}$ Institute für Sensor- und Informationssysteme (ISIS), Hochschule Karlsruhe - Technik und \\ Wirtschaft, Moltkestr. 30, D-76133 Karlsruhe, Germany, \\ ${ }^{2}$ DBFZ Deutsches Biomasseforschungszentrum gemeinnützige GmbH, Torgauer Straße 116, 04347 \\ Leipzig, Germany, \\ ${ }^{3}$ Sick AG, Erwin-Sick-Straße 1, 79183 Waldkirch, Germany, \\ Heinz.Kohler@hs-karlsruhe.de
}

\begin{abstract}
:
The sensing characteristics and long-term stability of different kinds of CO/HC gas sensors (nonNernstian mixed potential type) during in-situ operation in the flue gas of different types of low-power combustion systems (wood-log and wood-chips fueled) were investigated. The sensors showed representative but individual sensing behavior with respect to characteristically varying flue gas composition over the combustion process. The long-term sensor signal stability evaluated by repeated exposure to $\mathrm{CO} / \mathrm{H}_{2} / \mathrm{N}_{2} /$ synthetic air mixtures showed no sensitivity loss after operation in the flue gas. Particularly, for one of the sensors (Heraeus) this high signal stability was observed even during continuous operation over four months in the flue gas of a wood-chip firing system (field test). These results demonstrate that those sensors are appropriate for monitoring the combustion quality and implementation of advanced combustion process control.
\end{abstract}

Key words: Wood combustion systems, firing process control, gas sensors, mixed potential

\section{Introduction}

Small scale furnaces operated at domestic households, especially wood-log fueled heating systems and also wood chips/pellet fueled central heaters are well known to contribute considerably to air pollution by toxic emissions of un-combusted or partly combusted exhaust gas components $(\mathrm{CO} / \mathrm{HC})$ as well as particulate matter (PM) loaded with organics. Particularly in densely populated cities/villages and places where exchange of environmental air is hindered by landscape profile (e.g. location in a valley) or by temporary inversion situations in winter time, these emissions might accumulate and can create high risk for human-health [1, 2].

There have been several attempts to reduce those toxic emissions e.g. by improving the construction of the fireplaces and/or by introducing automatic combustion air stream control based on continuous measurement of combustion temperature (Tc) and residual oxygen concentration (ROC) in the flue gas by sensors. In contempt of those innovations, the emissions can be hardly controlled below the upper limits given by law (1. BImSchV) and in Germany, the overall immissions are still rising to alarming values in the last five years. From this point of view, it is obvious that the emissions of low-power wood combustion systems must be further reduced. In recent years, several studies have shown $[3,4,5]$ that firing process control can be further improved by additional introduction of an in-situ $\mathrm{CO} / \mathrm{HC}$ gas sensor and optimization of the air stream control algorithms. This results in tremendous reduction of toxic gas emissions of wood-log fueled single room fireplaces by up to $80 \%$ [6] compared to the emissions of hand operated (conventional) single room furnaces.

In addition, there is a high demand to monitor the combustion quality of automatically fed wood chip fueled furnaces. The gaseous emissions of those furnaces are comparably low as long as the system is operated at optimized conditions. However, continuous deposition of combustion residuals (ashes, soot, etc.) at the walls of the combustion chambers and heat exchanger tubes with long-term operation is known to have a negative influence on the combustion process and, correspondingly, can seriously reduce combustion quality and efficiency. In this context, appropriate and reliable $\mathrm{CO} / \mathrm{HC}$ sensing will allow to monitor the quality of combustion continuously and will enable routine cleaning and maintenance actions on demand to reduce costs and emissions and to increase utilization ratio. 
In this paper both aspects, improved process control of wood-log fueled firing and continuous monitoring of wood-chip fueled heaters by introduction of $\mathrm{CO} / \mathrm{HC}$-sensors are reported. In addition the question of $\mathrm{CO} / \mathrm{HC}$-sensor stability is discussed by comparing the signals of different simultaneously operated $\mathrm{CO} / \mathrm{HC}$ sensors in lab firing experiments and in a field test over several months.

\section{Experiments \\ Setups for sensor tests in the flue gas of wood combustion systems}

Firing experiments have been conducted with a wood-log fueled furnace (SF10SK, Brunner $\mathrm{GmbH}$, Eggenfelden, Germany) and two different wood chips fueled central heaters (Multifuel Central Heater, A.P. Bioenergietechnik, Hirschau, Germany). One of the latter was operated in the lab, the other was used in field test experiments over nearly four months during a winter season. All fireplaces were complemented by a sensor for measurement of ROC (LSU 4.9, Bosch) and different types of $\mathrm{CO} / \mathrm{HC}$ sensors, all positioned at the exhaust gas tube near the flue gas outlet of the firing system. The general concept of the construction of such fireplaces with primary and secondary combustion zone and the position of the gas sensors is given as schematic in Fig. 1.

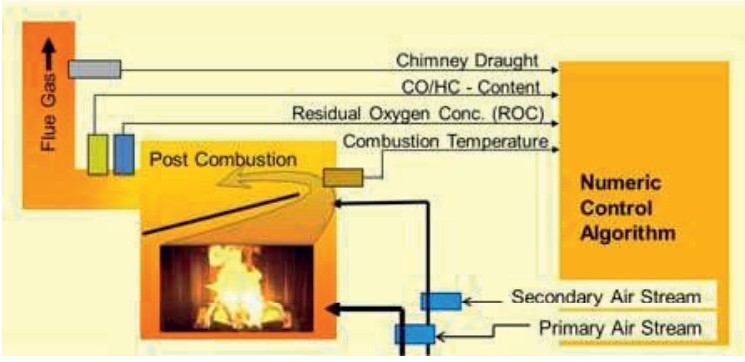

Fig. 1. Schematic drawing of a wood-log fueled fireplace with indication of the primary and secondary combustion air streams controlled by mass flow sensor/shutter systems (blue). The various sensor elements and their positions are depicted.

The wood-log fueled fireplace was additionally complemented with sensors for combustion air mass stream measurement (HFM7, Bosch $\mathrm{GmbH}$ ). The air streams were adjusted to desired flow by controlling the shutter position with separate nested control algorithms based on the sensor signals of air mass stream, combustion temperature (Tc), ROC and $\mathrm{CO} / \mathrm{HC}$ emissions $[3,4]$. This enables the application of those air stream control algorithms to fireplaces with natural chimney draught where different draught conditions have to be expected. These algorithms for air stream control were para- metrized for the SF10SK fireplace and the fireplace was used for comparative $\mathrm{CO} / \mathrm{HC}$ sensor evaluation in the flue gas. For the evaluation of the sensors in the exhaust gas of the wood-chip fueled firing system, the standard software of the producer was used for operating the system.

\section{CO/HC sensors under investigation for flue gas analysis}

The main focus of this work was to investigate the sensitivity and signal stability of different kinds of $\mathrm{CO} / \mathrm{HC}$ gas sensors which may be suitable for in-situ operation in the flue gas of low-power wood combustion systems. The availability of such long-term stable sensors at ambient temperatures in the range up to $500^{\circ} \mathrm{C}$ is the prerequisite for establishing the above mentioned new firing process control algorithms.

Commercially available high temperature (HT) gas sensors of the non-Nernstian mixed potential (MP) type, CarboSen (CS) $1 \mathrm{~K}$ and $10 \mathrm{~K}$ (Lamtec $\mathrm{GmbH}$ \& Co. KG, Walldorf) and a prototype sensor (HCS) for $\mathrm{CO} / \mathrm{HC}$ plus ROC measurement (Heraeus AG, Kleinostheim) have been investigated. The $\mathrm{CO} / \mathrm{HC}$ sensing concept of both kind of gas sensors is based on $\mathrm{Au}, \mathrm{Pt} / \mathrm{YSZ} / \mathrm{Pt}$ electro-chemical cells. An overview about the different sensor concepts is already reported in $[6,7]$ and details of the operation and signal generation of the Heraeus sensor chip are described in [8, 9].

The sensors are protected from particulate matter contaminations by a filter and generally, the sensors are in contact with a multitude of gas components (majorly $\mathrm{CO}, \mathrm{CH}_{4}$, Formaldehyde, organic acids, etc.) [10] which vary in concentration depending on the instant of firing situation (ignition phase, HT-phase (steady state), burn-out phase) and on the kind of wood used as fuel.

The CO/HC-sensors performance was studied by in-situ operation in the flue gas and simultaneously the flue gas composition was analyzed by extraction of a partial gas stream using a High-Temperature FTIR gas analysis system (GASMET, Ansyco GmbH, Karlsruhe). However, quantification of sensitivity and signal drifts during in-situ operation in the flue gas is not easily possible by referencing to the gaseous emissions recorded by a gas analysis system alone. The firing process and correspondingly the numerous components emitted are not well reproducible and vary considerably over time [10] and the MP-signals of all CO/HCsensors under investigation depend on many different components of the flue gas with different sensitivities [6]. To quantify long term stabi- 
lity under these operation conditions, the sensor elements were additionally calibrated in $\mathrm{CO} / \mathrm{H}_{2} / \mathrm{O}_{2} / \mathrm{N}_{2}$ model gas mixtures. This allows measurement of $\mathrm{CO} / \mathrm{H}_{2}$-equivalent concentrations $\left(\mathrm{CO} / \mathrm{H}_{2} \mathrm{e}\right)$ in the flue gas and enables the investigation of the signal stabilities by repeated exposure of model gases before and after insitu operation in flue gases by use of a standard gas mixing system [11].

\section{Results and discussion}

\section{Sensor behavior over time at in-situ operation in the flue gas}

Flue gas monitoring of wood-chip fueled central heater

The $\mathrm{CO} / \mathrm{HC}$-sensors under evaluation were operated in the flue gas of two wood-chip fueled central heaters of the same type (Nominal power (NP): $88 \mathrm{~kW}$ ) for different experimental intentions. Combustion experiments were carried out in the lab over about six hours a day. In between the firings the system was carefully
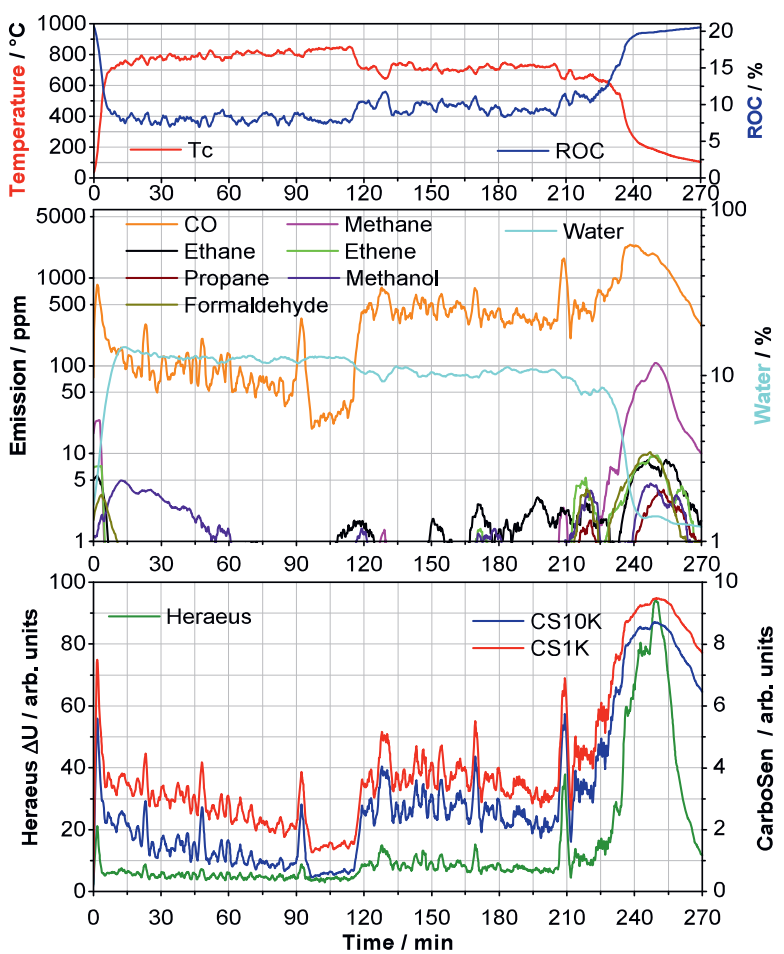

Fig. 2. Typical sequence of the sensor signals referenced to continuous flue gas analysis (FTIR) measured on the wood-chip fueled heater over time. The experiment started with cold ignition to steady state operation at $70 \% N P$, subsequent change to $50 \% N P$ at $120 \mathrm{~min}$ and after about 225 min the heater is operated down and stopped.

cleaned for getting reproducible combustion conditions. The signals of CS1K, CS10K and HCS over time of a typical test sequence are given in Fig. 2 together with the Tc, the ROC and the analysis of IR-active flue gas components by quasi continuous HT-FTIR analysis. After ignition, the system was operated at $70 \%$ of NP up to $120 \mathrm{~min}$, then reduced to $50 \%$ and the firing process was stopped at $225 \mathrm{~min}$. Operation at different heating power is correlated with different Tc and different concentrations of toxic gas emissions, especially CO. CS1K and CS10K behave rather similar. Mainly their signals follow the CO signal of the HT-FTIR system. In contrast, the signal of the HCS depends less on $\mathrm{c}(\mathrm{CO})$ but seems to be more estimated by $\mathrm{c}\left(\mathrm{CH}_{4}\right)$. Both types of sensors may show additional sensitivities to some HC-components. However, CS sensors are highly sensitive to $\mathrm{CO}$. Even $\mathrm{c}(\mathrm{CO})$ lower than 100 ppm are clearly recorded.

Significantly higher emissions are observed when the heater is continuously operated in the standard mode for heating of a settlement (field test) over months without any routine maintenance. Now emission peaks even higher than 1000 ppm CO (Fig. 3) are observed. The $\mathrm{CO} / \mathrm{H}_{2} \mathrm{e}$ values of both types of sensors over time follow quite well the course of $\mathrm{c}(\mathrm{CO})$ referenced by a standard portable CO-analysis instrument (SM500, Wöhler $\mathrm{GmbH}$ ).

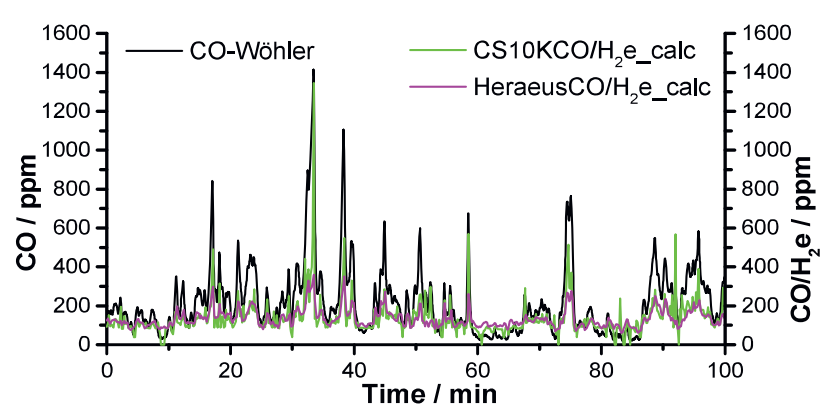

Fig. 3. Representative cut-out of the sensor signals of a CS10K and a HCS after a fourmonth operation sequence of the multifuel wood-chip fired central heater under field-test conditions.

\section{Flue gas monitoring of wood-log fueled fireplace}

The sensor signals of another set of $\mathrm{CO} / \mathrm{HC}$ sensors operated during a representative batch experiment on the wood-log fueled fireplace are visualized in Fig. 4 together with the flue gas FTIR-analysis, Tc and ROC. The experiment is based on different algorithms for air mass stream control of ignition phase, (IP, 0-10min), high temperature combustion phase (HTCP, 10-50min) and a burn-out phase (BOP, 50150 min). During HTCP the concentrations of emitted uncombusted components are very low. There is an obvious but not strong correlation of 
$\mathrm{ROC}$ and $\mathrm{CO} / \mathrm{HC}$-content with Tc. For example at the end of the IP the concentration of the HCs sharply decreases, Tc rises still beyond $700^{\circ} \mathrm{C}$ and ROC continuously falls (Fig. 4), but $\mathrm{c}(\mathrm{CO})$, is more or less constant. Only beyond minute $20 \mathrm{c}(\mathrm{CO})$ steeply falls to very low concentrations (Fig. 4) but there is also no simple, predictable correlation between $\mathrm{CO} / \mathrm{HC}$ content and $\mathrm{ROC}$ at relatively constant $\mathrm{TC} \cong$ $800^{\circ} \mathrm{C}$ in the HTCP. This example clearly demonstrates that for optimum air stream control of wood-log fueled fireplaces, the independent continuous measurement of $\mathrm{CO} / \mathrm{HC}$ content is necessary to enable optimized combustion.
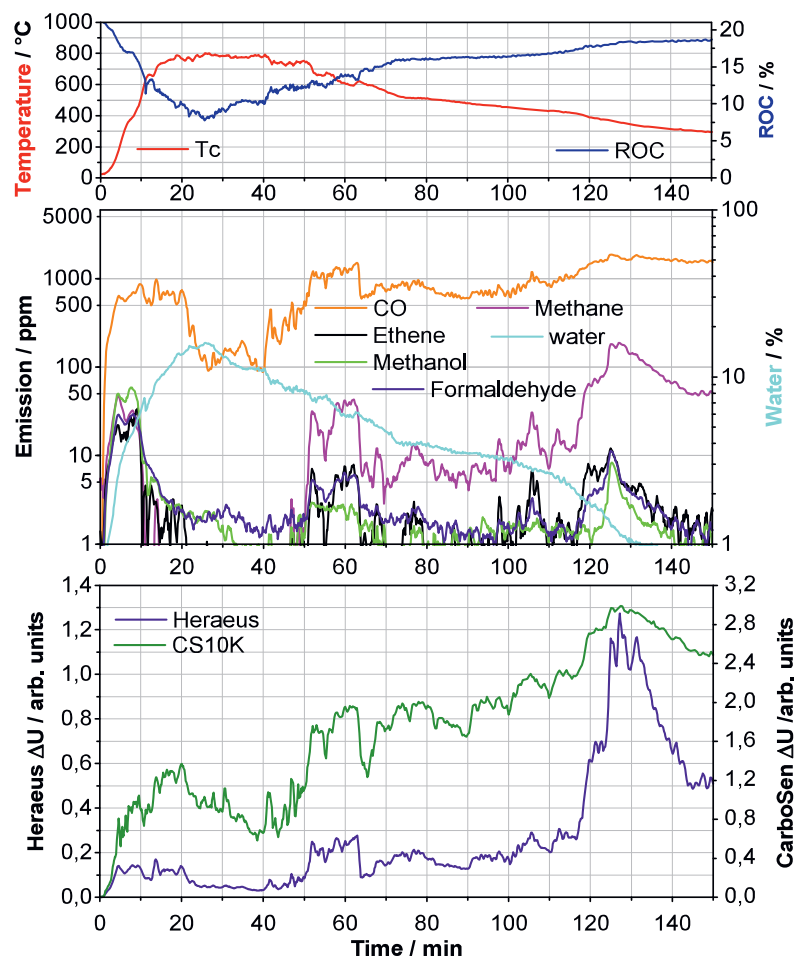

Fig. 4: Course of the sensor signals and FTIR flue gas analysis of a typical wood-log combustion batch firing experiment.

Regarding the courses of the signals of a CS10K and a HCS (Fig. 4), the response to different flue gas compositions is clearly different. The HCS-signal mainly seems to depend on $\mathrm{c}\left(\mathrm{CH}_{4}\right)$ and, perhaps, on some $\mathrm{HC}$-components. The CS10K-signal, however, may be more sensitive to $\mathrm{c}(\mathrm{CO})$ and on some organic gas components as well. The individual correlations of the signals with the flue gas components are still under investigation.

\section{CO/HC sensor stability}

The sensor signal stability was evaluated by repeated sensor signal measurement under exposure of $\mathrm{CO} / \mathrm{H}_{2} / \mathrm{O}_{2} / \mathrm{N}_{2}$ model gases. $\mathrm{An}$ overview of the results is given in Fig. 5. Both types of sensor have shown increased sensitivity after in-situ operation in the flue gas. The sensor signals of the HCS increased even after a four-month field test period.

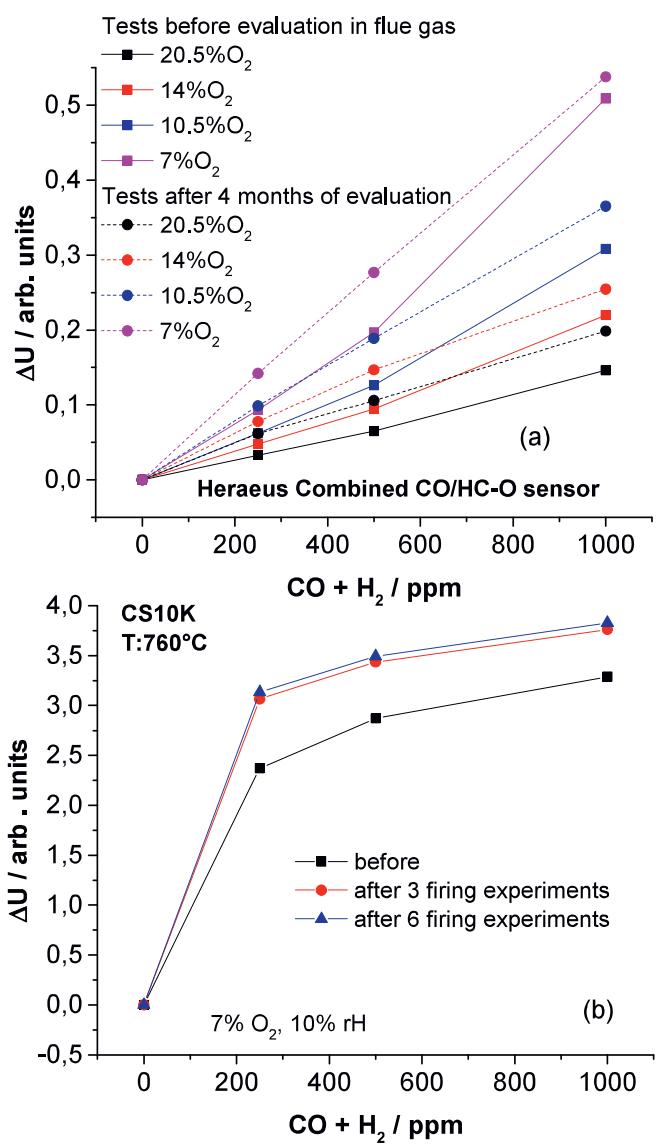

Fig. 5: Long-term stability evaluation by repeated sensor signal measurements. a) Sensor signals of HCS-sensor before and after four months operation in the flue gas of a woodchip central heater (field test) at different $c\left(\mathrm{O}_{2}\right)$, b) CS10K-signals in model gases with $7 \% \mathrm{O}_{2}-$ concentration before and after three and six batch wood-log fueled firing experiments, respectively.

\section{Conclusion and Outlook}

All sensor elements under investigation are of the non-Nernstian mixed potential (MP) type and therefore cannot represent individual gas components. In flue gas environment the sensor signal is generated by all reactive gas components, however, at individual sensitivities depending on the MP electrode material. Therefore, the sensor signals represent the flue gas composition and concentration in an individual manner. In this context, all sensor elements under study are generally suitable for monitoring of the combustion quality and for development of novel software for control of the 
combustion air streams to improve the combustion quality and reduce the toxic gas emissions. The signals of CS1K and CS10K sensor elements are well correlated to variation of $\mathrm{CO}$ emission, however the HCS sensor is more relating to the variation of $\mathrm{CH}_{4}$.

Further comparative studies will show the longterm stability of the different types of sensors when operated in the flue gas. As a highlight, one of the sensor elements (HCS) showed no signal loss even after four month of real life operation in the flue gas of a wood-chip combustion heater.

\section{Acknowledgement}

This project is funded by the Bundesministerium für Ernährung und Landwirtschaft (BMEL) and executed by Fachagentur für Nachwachsende Rohstoffe (FNR), Gülzow.

\section{References}

[1] M. Tapanainen, P.I. Jalava, J. Mäki-Paakkanen, P. Hakulinen, M.S. Happo, H. Lamberg, J. Ruusunen, J. Tissari, K. Nuutinen, P. Yli-Pirilä, R. Hillamo, R. O. Salonen, J. Jokiniemi, and M-R. Hirvonen, In vitro immunotoxic and genotoxic activities of particles emitted from two different small-scale wood combustion appliances, Atmospheric Environment 45, 7546-7554 (2011); doi :10.1016/j.atmosenv.2011.03.065

[2] N.K. Meyer, Particulate, black carbon and organic emissions from small-scale residential wood combustion appliances in Switzerland, Biomass and Bioenergy 36, 31-42 (2012); doi : 10.1016/j.biombioe.2011.09.023

[3] P. Butschbach, F. Hammer, H. Kohler, A. Potreck, Th. Trautmann, Extensive reduction of toxic gas emissions of firewood-fueled low power fireplaces by improved in situ gas sensorics and catalytic treatment of the exhaust gas, Sensors and Actuators B 137, 32-41 (2009); doi : 10.1016/j.snb.2008.12.007
[4] H. Kohler, S. Brunner, P. Butschbach, D. Glesing; Sensorik und Abgas-Katalyse zur Reduktion der Emissionen von Klein-Holzfeuerungsanlagen, Konferenz „Energetische Biomassenutzung Neue Technologien und Konzepte für die Bioenergie der Zukunft", Berlin, 5. Nov. 2012, Konferenzband Energetische Biomassenutzung, S. 80 ISSN 2192-1806 (2013)

[5] H. Kohler, A. Potreck, T. Trautmann; Verfahren und Vorrichtung zur Verbrennung von Brennstoffen; EP 2066972 B1 (2008)

[6] B. Ojha, N. Illyaskutty, J. Knoblauch, M. R. Balachandran and $\mathrm{H}$. Kohler, In-situ high temperature $\mathrm{CO} / \mathrm{HC}$ gas sensors for optimization of the firewood combustion in low power fireplaces, J. of Sensors and Sensor Systems (2017) just accepted.

[7] X. Zhang, H. Kohler, M. Schwotzer, U. Guth; Mixed-Potential Gas Sensor with Layered Au,PtYSZ Electrode: Investigating the sensing mechanism with steady state and dynamic electrochemical methods, Sensors \& Actuators $B$, (2017) under review process

[8] K. Wienand, Z. Matzvei, U. Karl-Heinz; Gassensor zur Messung unterschiedlicher Gase und zugehöriges Herstellungsverfahren, WO2014 198540 A1

[9] J. Zosel, C. Vonau, F. Gerlach, K. Ahlborn, K. Wienand, U. Guth; New materials for solid electrolyte sensors, Proceedings International Meeting on Chemical Sensors. Perth, Australia, 11.-13.07 (2010)

[10] R. Marutzky, K. Seeger; Energie aus Holz und anderer Biomasse, DRW-Verlag (1999)

[11] A. Jerger, H. Kohler, F. Becker, H.B. Keller, and R. Seifert, New applications of tin oxide gas sensors -II. Intelligent sensor system for reliable monitoring of ammonia leakages, Sensors and Actuators B 81, 300-307 (2002); doi : 10.1016/S0925-4005(01)00970-4 